\title{
SERANGAN DAN KERUSAKAN TANAMAN CENGKEH YANG DISEBABKAN OLEH Hexamitodera semivelutina Hell. DI DESA RERER KABUPATEN MINAHASA
}

\author{
ATTACKS AND DAMAGE TO CLOVE PLANT CAUSED BY Hexamitodera semivelutina \\ Hell. IN RERER VILLAGE OF MINAHASA DISTRICT
}

\author{
Christian Runaweri'1), J. Pelealu2), dan J. Manueke'2) \\ 1)Mahasiswa Entomologi Pascasarjana Unsrat Manado \\ 2)Dosen Fakultas Pertanian Unsrat Manado, 95115 \\ Email :cjoviar@gmail.com
}

\begin{abstract}
The aim of this research is to know the attack and damage of clove stem borer Hexamitodera semivelutina at some elevation in Rerer village of Kombi sub-district of Minahasa Regencyfor 2 months (February - April 2017). The research was conducted by survey on farmers' clove plantation area. The research was using a stratified random sampling method with observing the incidence and severity of $H$. semivelutina pest of clove plant. Treadment using 3 stratum height of place from sea level that is 0 $<300$ meters from sea level (mfsl), $300-<600$ (mfsl), and $>600$ (mfsl). The result of this research are the symptom of attack and damage of clove plant caused by $H$. Semivelutina pest as follows : incidence rate and severity according to altitude of place $0-<300 \mathrm{mfsl}$ are $24.67 \%$ and $12.55 \%$, while at height $300-<600 \mathrm{mfsl}$ are $42.34 \%$ and $22.88 \%$, and at altitude $>600 \mathrm{mfsl}$ are $61.67 \%$ and $33.66 \%$.
\end{abstract}

Keywords : incidence of pest, severity of pest, Hexamitodera semivelutina

\begin{abstract}
ABSTRAK
Penelitian bertujuan untuk mengetahui serangan dan kerusakan oleh hama penggerek batang cengkeh Hexamithodera semivelutina pada beberapa ketinggian tempat di Desa Rerer Kecamatan Kombi Kabupaten Minahasa selama 2 bulan yaitu dari bulan Februari sampai April 2017. Penelitian dilaksanakan secara survei pada areal perkebunan cengkeh milik petani. Penelitian menggunakan metode stratified random sampling dengan mengamati insidensi dan severitas hama $\mathrm{H}$. Semivelutina pada tanaman cengkeh. Perlakuan menggunakan 3 strata ketinggian tempat dari permukaan laut yaitu $0-<300$ meter dari permukaan laut (mdpl), $300-<600 \mathrm{mdpl}$, dan >600 mdpl. Hasil penelitian yang diperoleh adalah tingkat serangan dan kerusakan tanaman cengkeh akibat serangan hama $\mathrm{H}$. Semivelutina sebagai berikut: Insidensi dan severitas hama menurut ketinggian tempat dari permukaan laut yaitu 0 - <300 mdpl sebesar $24.67 \%$ dan $12.55 \%$, sementara pada ketinggian $300-<600$ mdpl sebesar $42.34 \%$ dan $22.88 \%$, dan pada ketinggian $>600$ mdpl sebesar $61.67 \%$ dan $33.66 \%$.

Kata kunci : insidensi hama, severitas hama, Hexamitodera semivelutina
\end{abstract}




\section{PENDAHULUAN}

Cengkeh (Syzygium aromatic cum, syn. Eugenia aromaticum), dalam bahasa Inggris disebut cloves, adalah tangkai bunga kering beraroma dari keluarga pohon Myrtaceae. Cengkeh adalah tanaman asli Indonesia, banyak digunakan sebagai bumbu masakan pedas di negara-negara Eropa, dan sebagai bahan utama rokok kretek khas Indonesia. Cengkeh ditanam terutama di Indonesia (Kepulauan Banda) dan Madagaskar; selain itu juga dibudidayakan di Zanzibar, India, dan Sri Lanka (Wokas, 1981; Anonim, 2003)

Di Indonesia tanaman cengkeh lebih kurang $95 \%$ diusahakan oleh rakyat dalam bentuk perkebunan rakyat yang tersebar di seluruh propinsi. Tahun 2004 tercatat luas areal pertanaman berkisar 429,935 Ha yang sebenarnya pada tahun 1982, luas areal telah mencapai $541,830 \mathrm{Ha}$ pada 26 propinsi (Hadiwijaya, 1986). Luas areal pertanaman cengkeh rakyat telah turun berkisar 120.000 Ha selama 20 tahun atau tiap tahun terjadi kerusakan $\pm 6000 \mathrm{Ha}$. Produktivitas cengkeh sangat rendah hanyalah $287,42 \mathrm{~kg} / \mathrm{ha} / \mathrm{panen}$. Dari data yang tercantum di atas terlihat bahwa budidaya tanaman cengkeh terdapat masalah dan kendala yang belum dapat diatasi petani cengkeh secara individu. Dari buku pedoman pengenalan dan pengendalian hama-penyakit cengkeh di Indonesia terdapat 5 hama utama dan berkisar 11 penyakit tanaman cengkeh yang melanda sentra pertanaman cengkeh di Indonesia belum termasuk penyakit fisiologi mati kekeringan dan mati bujang (Anonim, 2007).

Salah satu hama utama adalah penggerek batang cengkeh yang telah kronis pada beberapa propinsi. Di Provinsi Sulawesi Utara, pada tahun 1966, presentasi pohon cengkeh yang diserang penggerek batang cengkeh Hexamithodera semivelutina Hell (Cerambycidae, Coleoptera) dilaporkan mencapai $43,3 \%$ dengan angka kematian mencapai $14,2 \%$. Pada tahun 1974 pada sentra pertanaman cengkeh di Minahasa Tengah-Pinaras tercatat 35.000 pohon cengkeh terserang dan $14 \%$ rusak berat. Hasil penelitian Van Wyki, et.al., 2004 ternyata serangan penggerek batang cengkeh $H$. semivelutina sudah diikuti dengan serangan penyakit pembuluh batang oleh Ceratocystic polychroma. Sehingga tanaman cengkeh di Provinsi Sulawesi Utara mengalami banyak kematian pohon. Balai Proteksi Tanaman Provinsi Sulawesi Utara pada tahun 2007 melaporkan bahwa Penggerek Batang Cengkeh (PBC) H. Semivelutina telah eksplosif dan ditaksir daerah serangannya meliputi 18.838 $\mathrm{Ha}$ (serangan berat $18.723 \mathrm{Ha}$ dan serangan ringan $115 \mathrm{Ha}$ ) dan kehilangan hasil berkisar $161.011 \mathrm{~kg}$ cengkeh basah atau kerugian mencapai Rp 4.860.333.000. Ternyata sudah berkisar $46,61 \%$ dari tanaman cengkeh produktif yaitu \pm 40.418 pohon yang terserang PBC (Rondonuwu, dkk. 1980; Paath, dkk. 2005).

Hasil survei Mamahit dan Manueke tahun 2011 bahwa hampir semua areal pertanaman cengkeh di Minahasa sudah diserang oleh penggerek batang $\mathrm{H}$. semivelutina dan mengalami kerusakan yang berat. Bahkan pengendalian secara mekanis yang dilakukan oleh petani cengkeh dengan pelukaan pada batang cengkeh untuk mencari larva $H$. semivelutina mengakibatkan adanya gangguan pada pertumbuhan tanaman sehingga memperparah kerusakan tanaman cengkeh.

Gejala serangan pada batang pohon cengkeh adalah dengan terlihatnya lobang berukuran 3-5 $\mathrm{mm}$ yang mengeluarkan sisa-sisa gerekan dan kotoran serangga yang mengalir ke bawah. Pada satu pohon cengkeh dapat ditemukan berkisar 10-20 lubang gerekan dan apabila lubanglubang tersebut dibuka maka akan terlihat saluran/ liang yang menghubungkan lubang-lubang tersebut. Liang-liang gerekan tidak teratur dan apabila liang gerekan melingkari batang maka bagian tanaman di atas liang tersebut menunjukkan gejala meranggas dan mengakibatkan kematian tanaman (Rondonuwu, dkk. 1980; Tarore dan Manueke, 2007). 
Batang yang sedang terserang, dari lubang gerekan terlihat basah, mengeluarkan cairan coklat bercampur dengan kotoran bekas/sisa gerekan yang halus seperti butiran pasir atau tepung. Keadaan demikian menunjukkan bahwa larva ada di dalam liang gerekan dan sedang menyerang, sehingga lubang gerekan tersebut disebut lubang aktif. Jumlah lubang gerekan pada batang cengkeh berkisar $20-40$ buah dan rata-rata 30 buah, kadang-kadang dapat mencapai 100 buah lubang yang membentuk liang-liang gerekan yang tidak teratur. Panjang liang/saluran gerekan dari lubang teratas sampai lubang terbawah $\pm 2 \mathrm{~m}$, ada yang hanya $1 \mathrm{~m}$, dan rata-rata $1,5 \mathrm{~m}$, tergantung pada besarnya batang yang diserang dan stadium larva yang menyerang. Kerusakan pada batang, cabang maupun akar terjadi pada jaringan kambium, phloem dan xylem, sehingga menyebabkan pertumbuhan tanaman terhambat bahkan tanaman dapat mengalami kematian (Warouw, 1975; Rondonuwu, dkk., 1980; Tarore dan Manueke, 2007).

\section{METODE PENELITIAN}

Penelitian menggunakan metode stratified random sampling dengan mengamati insidensi dan severitas hama $H$ Semivelutina pada tanaman cengkeh. Perlakukan menggunakan 3 strata ketinggian yaitu , $0-<300$ meter dari permukaan laut (mdpl) $300-<600 \mathrm{mdpl}$, dan >600 mdpl.
Parameter pengamatan meliputi gejala serangan dan kerusakan dari masing-masing ketinggian tempat dari atas permukaan laut, untuk menghitung insidensi dan severitas digunakan rumus :

$$
\text { Insidensi }=\mathrm{DI}=\stackrel{\mathrm{n}}{\mathrm{N}} \times \mathbf{x}
$$

$\mathrm{DI}=$ Insidensi hama (\%), $\mathrm{n}=$ Jumlah pohon terserang, $\mathrm{N}=$ Total jumlah pohon yang diamati

Severitas $=D S=\frac{\sum(n \times v)}{N \times V}$

DS = Severitas hama (\%), $\mathrm{n}=$ Jumlah pohon cengkeh yang sama skor-nya, $v=$ Skor dari setiap kategori kerusakan, $\mathrm{N}=$ Jumlah pohon cengkeh yang diamati, $\mathrm{V}=$ Skor tertinggi dari kategori kerusakan (Warouw, dkk. 1975)

\section{HASIL DAN PEMBAHASAN}

Batang cengkeh yang terserang $H$. semivelutina seringkali lubang gerekan bersifat melingkar/menggelangi batang sehingga hama ini dikenal juga sebagai penggerek batang melingkar. Kerusakan berat akibat serangan $H$. semivelutina adalah mahkota pohon tidak rimbun, daun-daun hampir $70 \%$ rontok dan sebagian cabang, daun, dan ranting mati. Daun berubah dari warna hijau tua menjadi hijau kekuningan dan akhirnya gugur. Gejala serangan dan kerusakan tanaman cengkeh yang diserang hama penggerek batang cengkeh $H$. semivelutina dapat dilihat pada Gambar 1 dan 2.

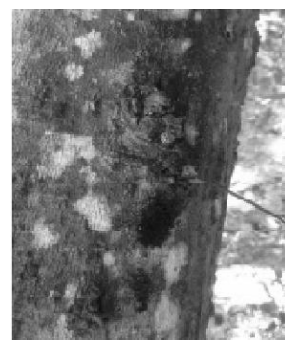

A

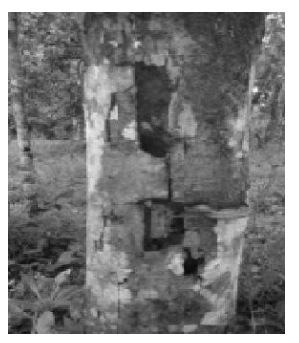

B

Gambar 1. Gejalah Serangan H. semivelutina Pada Batang Tanaman Cengkeh Keterangan : $\mathrm{A}=$ Lubang Gerekan Aktif, $\mathrm{B}=$ Lubang Gerekan Tidak Aktif

(Figure 1. Symtoms of $\mathrm{H}$. semivelutina Attact on Clove Plant Stems)

Note $\quad: A=$ Active Hoist Holes,$\quad B=$ Not Active Hoits Holes 


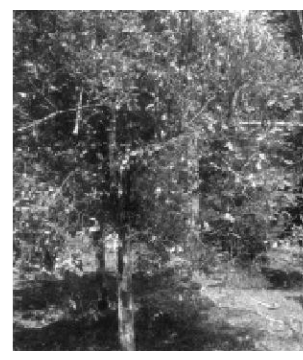

A

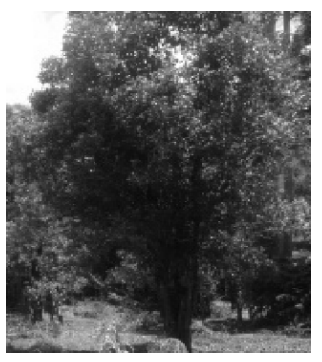

B

Gambar 2. Gejala Serangan Pada Kanopi (di Atas Tanah). Keterangan : $\mathrm{A}=$ Tanaman Terserang, $\mathrm{B}=$ Tanaman Sehat

(Figure 2. Symtoms of $\mathrm{H}$. semivelutina Attact on Clove Plant Canopy (on the Ground))

Note : $\quad A=$ Attact Plants $\quad B=$ Healthy Plants

Gambar 1 dan 2 menunjukkan bahwa serangan $H$. semivelutina pada tanaman cengkeh dapat berupa kerusakan mekanis pada batang dan gugurnya daun pada kanopi tanaman sampai tanaman tidak dapat berproduksi secara maksimal dan kerusakan dapat mencapai $75 \%$ dari suatu areal perkebunan yang luas. Pohon yang digerek hidupnya merana dan lama kelamaan menjadi kering dan mati. Apabila ada angin kencang pohon dapat tumbang (Paath, dkk. 2005; Rondonuwu, $d k k, 2011)$.

Hasil pengamatan kerusakan pada tanaman cengkeh akibat serangan hama $H$. semivelutina menunjukkan bahwa insidensi dan severitas pada ketinggian 0 - $<300$ mdpl lebih sedikit $24.67 \%$ dari pada ketinggian 300 - >600 mdpl yang hanya $42.34 \%$ sedangkan pada ketinggian $>600 \mathrm{mdpl}$ tingkat insidensi dan severitas lebih besar yaitu $61.67 \%$. Hal ini menunjukkan bahwa tingkat serangan dan kerusakan tanaman cengkeh akibat serangan $\mathrm{H}$. semivelutina berbanding lurus dengan ketinggian tempat dari permukaan laut. Makin tinggi tempat dari permukaan laut makin tinggi pula serangan dan kerusakan oleh $H$. semivelutina pada tanaman cengkeh (Tabel 1).

Garret (2006) menyatakan bahwa dampak yang paling besar yang berpengaruh pada perkembangan serangan hama adalah pada ekosistem pertanian yang dapat menyebabkan terjadinya perubahan populasi hama akibat peningkatan suhu dan perubahan curah hujan. Bonaro, dkk. (2007) juga menyatakan perkembangan hama dipengaruhi oleh iklim, temperatur, dan kelembaban udara baik langsung maupun tidak langsung yang berpengaruh langsung terhadap siklus hidup, keperidian, lama hidup, serta kemampuan diapause serangga. Menurut Capinera (2012) bahwa ketinggian tempat berpengaruh pada perbedaan suhu, kelembaban udara, dan angin yang mempengaruhi penyebaran serangga.

Rahayu (2012) menyatakan bahwa ketinggian tempat erat kaitannya dengan suhu udara yang memegang peranan penting dan sering menjadi faktor pembatas karena mempengaruhi kecepatan proses metabolisme dan kehidupan serangga dalam berbagai segi antara lain aktivitas makan serangga, dan perkembangannya. Stafford (2008) menyatakan pengaruh kenaikan suhu terhadap perkembangan serangga hama dalam kondisi suhu optimum adalah kecepatan proses metabolisme serangga hama berbanding lurus dengan kenaikan suhu lingkungan. Hal ini berarti apabila suhu naik, proses metabolisme serangga bertambah cepat. Proses metabolisme di dalam tubuh serangga hama merupakan fenomena fisika kimia yang kompleks. 
Tabel 1. Kerusakan Tanaman Cengkeh Akibat Serangan Hama H Semivelutina di Desa Rerer Kabupaten Minahasa

(Table 1. Damage to Clove Plants Due to H. semivelutina)

\begin{tabular}{ccccc}
\hline No. & Tinggi tempat dari permukaan laut & Insidensi $(\%)$ & Severitas $(\%)$ & Keterangan \\
\hline 1. & $0-<300 \mathrm{mdpl}$ & $24.67 \%$ & $12.55 \%$ & 100 pohon contoh \\
2. & $300-<600 \mathrm{mdpl}$ & $42.34 \%$ & $22.88 \%$ & tiap ketinggian \\
3. & $>600 \mathrm{mdpl}$ & $61.67 \%$ & $33.66 \%$ & \\
\hline
\end{tabular}

Intensitas serangan penggerek batang cengkeh lebih berat pada musim penghujan dibandingkan dengan musim kemarau. Kerusakan yang ditimbulkan oleh larva disebabkan karena larva memakan jaringan batang dengan cara menggerek jaringan-jaringan pada batang, cabang, adakalanya sampai ke akar. Larva biasanya menggerek ke arah bawah pada permukaan bawah kulit batang $1-3 \mathrm{~cm}$, tetapi ada juga yang menggerek ke dalam batang $3-5 \mathrm{~cm}$. Liang-liang gerekan yang dibuat secara tidak beraturan, ada yang mengarah ke bawah, ke dalam, dan paling berbahaya adalah liang gerekan yang menggelangi batang (Warouw, dkk, 1975; Lubis, 1983).

Umur tanaman cengkeh yang terserang setelah dilakukan pengamatan yaitu tanaman sudah berumur 10 tahun ke atas. Menurut Rondonuwu, dkk. (1980) ada hubungan yang sangat nyata antara umur tanaman dan serangan hama. Semakin tua tanaman semakin tinggi serangannya. Akibat dari serangan penggerek batang ini daun mula-mula berubah warna menjadi kekuningan dan kemudian rontok, akibat lebih lanjut terjadi mati pucuk dan pada serangan berat dapat mengakibatkan kematian tanaman. Keadaan tanaman pada saat penelitian berada pada kondisi tanaman yang pucuknya atau pada bagian atas pohon mulai mengering.

Berdasarkan hasil pengamatan di lapangan para petani belum pernah melakukan pengendalian terhadap serangan hama penggerek batang cengkeh. Hal ini yang menyebabkan serangan hama pada ketiga lokasi menurut ketinggian sangat berbeda. Dhalimi (1987) menyatakan bahwa apabila pengendalian hama $H$. semivelutina kurang diperhatikan, dapat mengakibatkan semakin luas- nya serangan, yang berarti semakin besarnya kerugian produksi untuk cengkeh.

\section{KESIMPULAN}

Gejala serangan $H$. semivelutina yaitu adanya lubang gerekan pada batang dan gugurnya daun pada kanopi tanaman cengkeh sampai tanaman tidak dapat berproduksi secara maksimal. Insidensi dan severitas hama menurut ketinggian tempat dari permukaan laut yaitu $0-<300 \mathrm{mdpl} \mathrm{se-}$ besar $24.67 \%$ dan $12.55 \%, 300-<600 \mathrm{mdpl}$ sebesar $42.34 \%$ dan $22.88 \%$, dan $>600$ mdpl sebesar $61.67 \%$ dan $33.66 \%$.

\section{DAFTAR PUSTAKA}

Anonim. 2003. Revitalisasi Industri Cengkeh Nasional. Makalah dalam Seminar Pembangunan Tanaman Industri di Sulawesi Utara. Juli 2003. 18 Hal (tidak dipublikasi).

------, 2007. Rekapitulasi Luas Areal dan Produksi Tanaman Perkebunan Menurut Keadaan Pertanaman Perkebunan Rakyat di Sulawesi Utara Tahun 2007. Disbun Sulut Manado 2007.

Bonaro, O., A. Lurette, C. Vidal, and J. Fargues. 2007. Modelling Temperature dependent Bionomics of Bemisia tabaci (Q-biotype) Physiological Entomology,32: 50-55.

Capinera, J.L. 2012. Sweetpotato Weevil, Cylas formicarius (Fabricius) (Insecta: Coleoptera: Brentidae (Curculionidae)). https://edis.ifas.uff.edu/in154capineraspw1 
Garret, K.A. 2006. Climate Change Effect to Plant Disease: Genome to Ecosystem. Ann, Rev. Phytopathol 44: 489- 509.

Lubis, H.A.M. 1976. Pedoman dan Hama Tanaman Cengkeh. Departemen Pertanian Direktorat Jenderal Perkebunan. Jakarta.

Mamahit, J.E.M. dan J. Manueke. 2011. Survei Serangan Penggerek Batang Cengkeh (Hexamithodera semivelutina Hell) Di Kabupaten Minahasa Provinsi Sulawesi Utara. Fakultas Pertanian Universitas Sam Ratulangi. Manado.

Paat, J.M., B.H. Assa, E.C.Y. Liew, D.T. Sembel, F.A. Warouw, and L.W. Burgess, 2005. Distribution, Incidence and Severity of Clove Leaf Fall Disease in Minahasa, North Sulawesi. Phytopatology ICCS. $10 \mathrm{pp}$.

Rahayu, E. 2012. Faktor-Faktor yang Mempengaruhi Kehidupan Serangga. http://kuliahagribisniselin.blogspot.com.

Rondonuwu, S.J., M. Karouw, F. Kaseger, O. Rondonuwu, E. Awuy, dan V. Rantung. 1980. Intensitas Serangan, Pola Penyebaran dan Bionomi Serangga Hama Penggerek Batang Cengkeh (Hexamitodera semivelutina HELL.) di Minahasa. Laporan Hasil Penelitian. 49 hal.
Stafford, K.C. 2008. Fly Management Handbook: a Guide to Biology, Dispersal, and Management of the House Fly and Related Flies for Farmers, Municipalities, and Public Health Officials Connecticut Agri-cultural Experiment Station, New Haven. Bulletin 1013. May 2008. 40.

Tarore, D. dan J. Manueke 2007. Intensitas Serangan Hama Penggerek Batang Hexamithodera semivelutina pada Tanaman Cengkeh. Fakultas Pertanian Universitas Sam Ratulangi. Manado.

Van Wyk M, J. Roux, I. Barnes, B.D. Wing Field. E.C.Y. Liew, B. Assa, A.B. Summereel and M.J. Wing Field. 2004. Cerotocystis polychromo. Nov., a New Species from Syzygium aromaticum in Sulawesi. Studies in Mycology 50 : 273-282.

Warouw, J., P.P. Pakasi, A. Komaling, H. Kawulusan, S. Sumanauw dan B. Masinambouw. 1975. Proyek Kerjasama Dinas Perkebunan Rakyat Dati I Sulawesi Utara dan Fakultas Pertanian Universitas Sam Ratulangi. Manado.

Wokas, F.H.M. 1981. Cengkeh (Eugenia caryophyllus Sprengel). Fakultas Pertanian Universitas Sam Ratulangi. Manado. 